\title{
THE IMPORTANCE OF SOCIAL SUPPORT AS A DRIVER OF IMPROVEMENT IN THE TREATMENT OF BREAST CANCER
}

\author{
Ianca L. Santos ${ }^{1}$, Paula de O. C. Queiroz¹ Edras A. F. Souza1 \\ ${ }^{1}$ Faculdade de Medicina, Universidade Federal de Goiás - Goiânia (GO), Brazil.
}

Objective: It is known that people who receive considerable social support in stress situations have minor negative effects on their health and social well-being. Therefore, this study aimed to evaluate the importance of social support as a driver of improvement in the treatment of breast cancer. Methodology: This is a narrative review and aims to describe the development regarding the importance of social support as a driver of improvement in the treatment of breast cancer. The search for articles occurred through access to platforms such as SciELO - Scientific Electronic Library Online and Scholar. The period of publications of the articles chosen was from 2010 to 2017, and the terms delimiters used were: research social support, treatment, and breast cancer. Results: Social support in the fight against breast cancer is of fundamental importance for a better treatment. Besides religiosity and science itself, the attachment to social support, be it with friends, family or even people who are going through the same disease is fundamental for an improvement of the patient. According to the work published in the UFPE Nursing magazine by the nurse Keli Regiane Tomeleri da Fonseca Pinto, social support changes the way patients see the disease because it brings more courage and encouragement to face it, as well as more hope about their state of health. Finally, it is of fundamental importance the social support to the patient, since besides improving the physical state of the patient, it also improves his psychological state, and this is of fundamental importance for the cancer healing process. Conclusion: Social support has positively impacted the treatment of breast cancer. When inserted into an integral network of care, the woman strengthened her relationships with family and community. It is also mentioned that, in addition to empowering, it deals in a more progressive way with its health-disease process. 